\title{
A fotografia como prática conversacional de dados. Espacialização e sociabilidade digital no uso do Instagram em praças e parques na cidade de Salvador ${ }^{1}$
}

\section{Photography as conversational data practice. Spatialization and digital sociability in the use of Instagram in squares and parks in the city of Salvador}

André Lemos ${ }^{2}$

Leonardo Pastor

Resumo: Este artigo investiga empiricamente a prática fotográfica através do aplicativo Instagram. Foram analisadas 305 imagens associadas à geolocalização de quatro praças e parques da cidade de Salvador. A análise foi desenvolvida através de três aspectos: processo de espacialização, processo de sociabilidade e processo de produção de si (retratos e selfies). O uso de metatexto (hashtags, legendas e emojis) e de dados de geolocalização indicam que a prática fotográfica se dá, hoje, como uma prática conversacional de dados. Ela convoca uma ampla rede que passa pelo local escolhido, pelo artefato utilizado, pelas formas de edição e manipulação da imagem, pelos metatextos, pelas geotags, pelo procedimento algorítmico da rede social, pelas formas de compartilhamento... O uso da fotografia em redes sociais é um ator-rede, performativo, algorítmico, muito diferente da prática de produção de fotos analógicas ou mesmo digitais antes do

1 Este artigo é parte da pesquisa "A comunicação das coisas. Internet das coisas, big data e smart cities" (CNPQ/303461/2013-6), desenvolvida no Laboratório de Pesquisa em Mídia Digital, Redes e Espaço (Lab404) do Programa de Pós-graduação em Comunicação e Cultura Contemporâneas (Faculdade de Comunicação da UFBA). Agradecemos a Michelle Oliveira, graduanda em jornalismo e bolsista do Lab404 (Póscom/UFBA), pela ajuda na coleta e no tratamento dos dados.

2 Universidade Federal da Bahia. Salvador, BA, Brasil. E-mail: leopbr@gmail.com

3 Universidade Federal da Bahia. Salvador, BA, Brasil. E-mail: almlemos@gmail.com 
surgimento dessas redes. Isso possibilita aos usuários a criação de um discurso/ narrativa e de uma prática de dados relacionados à fotografia inédita até então.

Palavras-chave: fotografia; espaço urbano; Instagram; mediação; Salvador

Abstract: This paper aims to empirically investigates the new photographic practice through Instagram application. We studied 305 images associated to four urban spaces (squares and parks) in Salvador, Bahia through the sociability process, the production of space and the self-portraits (including selfies). The analysis points out that the use of meta-textes (hashtags, subtitles and emojis), as well as the geolocation data indicate that the photographic practice is based in a data-driven conversational communication. This practice deploys an extensive network of objects and agencies (artefact, image editing and manipulation, meta-texts, geotags, algorithmic procedure, sharing practices ...). We are dealing with an "actor-network" based in an algorithmic performativity very different from the photographic practice with analogical cameras or even with digital cameras prior the boom of digital social network. Users are now able to create a new discourse / narrative and a practice of data related to the photograph.

Keywords: photography; urban space; Instagram; mediation; Salvador 


\section{Introdução}

Ao observar o movimento cotidiano em espaços públicos urbanos, é possível perceber a presença constante de dispositivos móveis servindo como mediadores da interação entre as pessoas e os locais, na maioria das vezes com o suporte de uma rede social (Facebook, Twitter, Instagram, para citar as mais usadas). Mais do que com câmeras fotográficas dedicadas, ou mesmo tablets, é através dos smartphones que a prática da fotografia se exerce (SMARTPHONES, 2016; 700 MILLION, 2017; LENSVID EXCLUSIVE, [2017?]). Esses dispositivos tornam cada vez mais banal o ato de tirar e compartilhar fotos, transformando-o em uma atividade associada à prática de dados (LUPTON, 2016), com a produção de georreferenciamento e metatextos, como legendas e hashtags. Da fotografia analógica de arquivamento em álbuns de família (BOURDIEU, 1965), passamos para uma prática fotográfica realizada predominantemente como vetor de comunicação e sociabilidade, comprovada pela prevalência do contato com o outro - em detrimento da preocupação com a qualidade técnica da imagem - e do acréscimo de novas camadas informacionais através de geolocalização, textos, hashtags e emojis.

A fotografia digital produz um sentido de copresença e enraizamento no lugar (emplacement) através de movimento e relações entre pessoas, imagens e artefatos (HJORTH; PINK, 2014). Nesse entrelaçamento entre experiência, formas locativas e representação (HJORTH; HENDRY, 2015), as mídias sociais voltadas para a prática fotográfica - especialmente aquelas vinculadas a aplicativos para smartphone, como o Instagram - se tornam mediadoras na formação dessas novas visualidades e interações. Esta pesquisa vai comprovar que esse entrelaçamento se dá através de uma prática fotográfica vinculada não apenas à imagem, mas às diferentes interações textuais com dados registrados a partir de textos de legenda ou comentários, hashtags adicionadas à publicação ou likes gerados por aqueles que visualizaram e reagiram à foto.

A fotografia em redes sociais se torna um ator-rede (LATOUR, 2005), pautada pela performatividade algorítmica e pela prática de produção 
de dados. Ela se diferencia, portanto, das formas de espacialização e sociabilidade promovidas pela atividade fotográfica realizada através de câmeras analógicas ou de imagens digitais sem a interação com redes sociais na internet. Como analisaremos neste artigo, os processos de produção de si, de espacialização e de sociabilidade se transformam de maneira a agregar uma prática conversacional de dados produtora de narrativas - guiadas pela própria prática fotográfica dos usuários e pela leitura e performatização do sistema - em meio a redes de agências múltiplas de humanos e não humanos.

Esta pesquisa aponta para a materialidade da prática no Instagram e para o caráter comunicacional da foto em redes sociais. Com isso, confirmamos que a prática da fotografia digital em redes sociais significa menos a fixação de uma memória de momentos solenes, de cuidado com a imagem, e mais de contato com o outro, de compartilhamento de sentimentos imediatos, de formas explícitas de sociabilidade com metadados que extrapolam a imagem. Em um dos tipos de fotografia mais praticados hoje, a selfie, importa menos a foto isoladamente e mais o momento, o compartilhamento e a relação com o espaço e o outro. Isso vale não só para o autorretrato, mas para todas as fotografias circulando em redes sociais. Fotografar com um celular e veicular as fotos em redes sociais convoca uma outra rede (diversa da foto analógica ou mesmo da digital antes das redes sociais) na qual o dado passa a ser um elemento fundamental, não só como digitalização e algoritmo controlador dos aplicativos e da internet, mas também como metatexto colocado voluntariamente pelos usuários (hashtags, legendas e emojis).

\section{Metodologia e primeiros resultados}

A coleta de publicações no Instagram se deu entre os dias 21 e 31 de janeiro de 2017. Utilizamos os locais de Salvador que apresentaram uma média de, no mínimo, três fotos publicadas diariamente e que fossem de acesso livre e público, a fim de captar um uso mais cotidiano do espaço. Identificamos quatro locais: Parque da Cidade, Parque de Pituaçu, Praça Ana Lúcia Magalhães e Dique do Tororó. Selecionamos para 
análise todas as publicações desse período disponibilizadas de forma pública e registradas com a respectiva geolocalização. O recorte temporal, portanto, nos permitiu trabalhar com um conjunto amplo de diferentes práticas de sociabilidade, interação e representação do espaço.

Foi feita uma extração ${ }^{4}$ de todas as publicações, incluindo, além da própria informação imagética, legendas, comentários, likes, emojis, marcações, geolocalização $e$ hashtags. O único ponto de partida em comum, para cada local, foi a informação registrada em formato de geolocalização. Foram identificadas um total de 305 publicações: 39 no Dique do Tororó, 162 no Parque da Cidade, 64 no Parque de Pituaçu e 40 na Praça Ana Lúcia Magalhães. Após a extração, todas as imagens foram importadas para o software de análise qualitativa Atlas.ti, através do qual foram desenvolvidas codificações 5 em diferentes níveis.

Em uma primeira análise geral, agrupamos três tipos principais de fotografia: objeto (qualquer forma de natureza morta ou objeto), paisagem (natural e/ou urbana) e retrato (individuais, coletivos ou autorretrato). As fotos de objetos foram as de menor número (13), seguidas das de paisagem (42) e de retrato (253). Uma publicação pode apresentar mais de uma imagem através de montagem. Nesse caso, ela foi relacionada a mais de um tipo de fotografia. Em seguida, as publicações foram identificadas quanto a temáticas ${ }^{6}$ ou itens presentes nas imagens, como atividade física (54), criança (50), natureza (45), animais (21), família (16) etc. Os retratos foram identificados quanto a características mais específicas, como individual (107), selfie (88), grupo $^{7}$ de pessoas (82) ou

4 As publicações foram extraídas em formato PDF, permitindo a visualização tanto da imagem quanto de textos identificáveis. Para garantir um backup das informações textuais, utilizamos também a extensão Data Miner para o navegador Chrome, aplicando-a em cada local selecionado (https://data-miner.io/).

5 O Atlas.ti permite um trabalho de pesquisa baseado em criação de códigos que podem ser desenvolvidos no decorrer de leituras ou observação do material coletado, sejam imagens ou textos, ampliando as possibilidades de análise.

6 Identificamos possíveis temáticas, itens ou relações específicas que cada foto pode apresentar. Foram encontrados 24: amizade, animais, aniversário, arte, atividade física, bebida, chá de bebê, comida, criança, dança, efeitos especiais, família, fotografia, leitura, moda, música, natureza, parte do corpo, pesca, piquenique, pôr do sol, relacionamento amoroso, religiosidade e trabalho.

7 Consideramos como "grupo" quando há mais de duas pessoas na imagem. 
duplas (56). Essas codificações nos auxiliam na percepção de relações e descrições realizadas a partir da análise do material coletado.

Em uma segunda etapa de análise, tratamos dos metatextos vinculados às imagens. Inicialmente, portanto, foi realizado um levantamento de todas as hashtags utilizadas nas publicações da amostra. As 10 mais comuns, acompanhadas da frequência em número de aparições, são: \#parquedacidade (16), \#salvador (13), \#bahia (10), \#livreslivros (5), \#mundodalua (5), \#photooftheday (5), \#ssalovers (5), \#leitura (4), \#tbt (4), \#adoteumcaoadulto (3).

Figura 1 - Nuvem de todas as hashtags utilizadas.

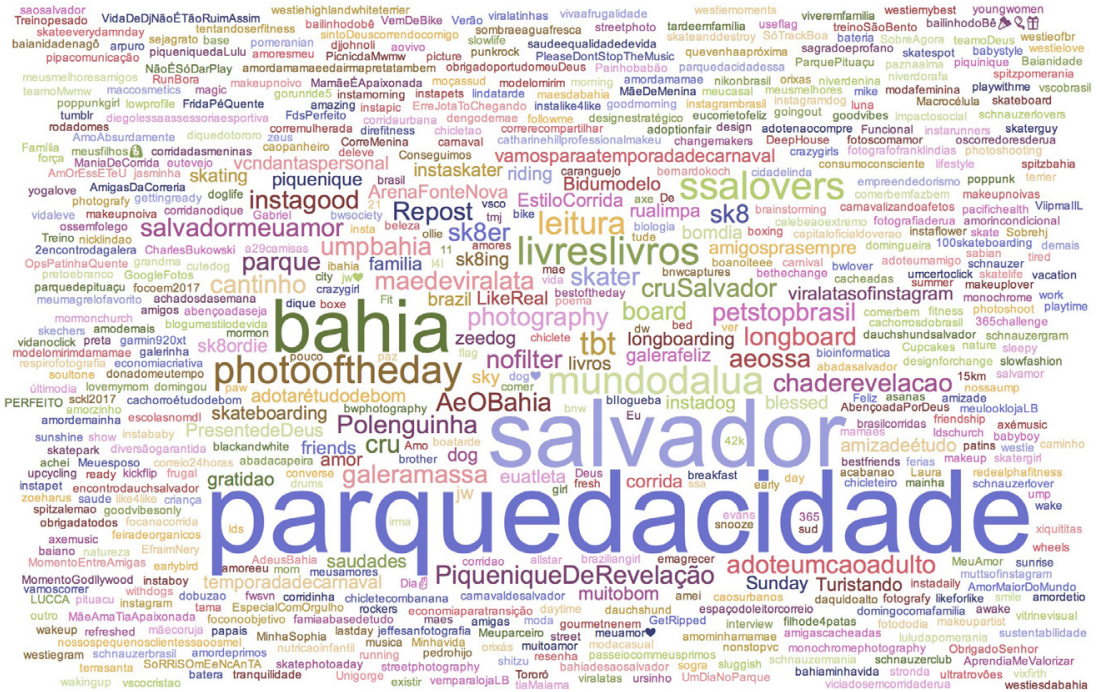

Observando as hashtags, percebe-se uma grande diversidade e que elas são produzidas mais em função de sua expressividade do que por uma lógica de etiquetagem. Pode-se inferir esse comportamento ao perceber o número baixo de repetições, além de diferentes hashtags a representar atividades específicas em vez da utilização de termos gerais visando a algum tipo de indexação (\#saudeequalidadedevida, \#cachorroetudodebom, \#MomentoEntreAmigas etc). Do ponto de vista do usuário, a intenção de indexação se mostra menos recorrente. No entanto, muitas hashtags são produzidas para a identificação do local 
(Parque da Cidade ou cidade de Salvador ou estado da Bahia, por exemplo). A intencionalidade de escapar de uma lógica de etiquetagem, por outro lado, não exclui as possibilidades de etiquetagem realizadas pela própria rede social, pois se trata de uma tag. Portanto, a fotografia, ao se transformar em conjunto de dados em uma publicação, mantém constantemente as possibilidades de correlações, indexações e agrupamentos realizadas pelo sistema: textos em legendas e comentários, perfis que interagem, a imagem indexada através de leituras algorítmicas.

Figura 2 - Metatextos em legenda por publicação.

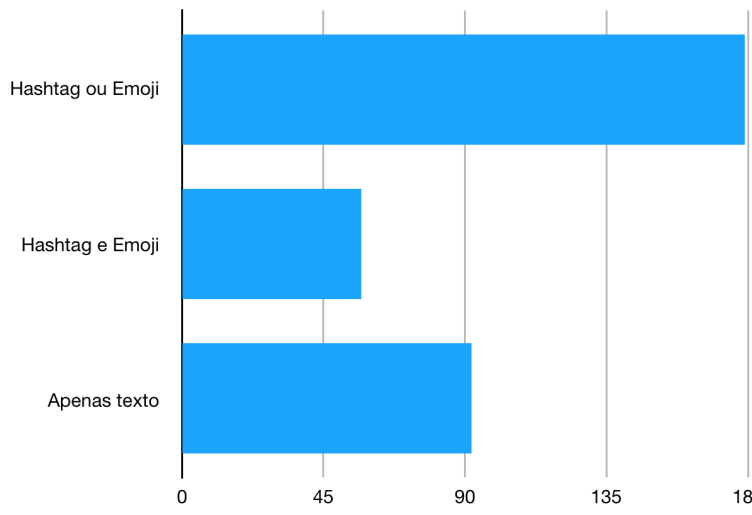

Sem metatextos Com metatextos

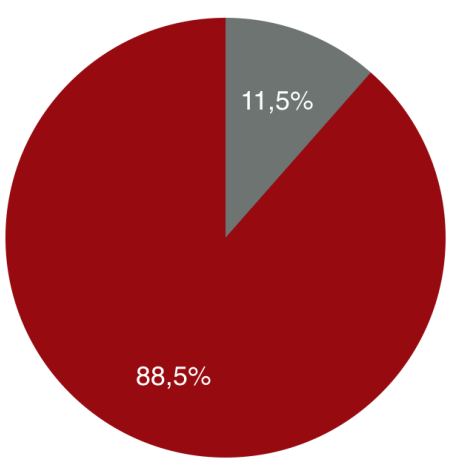

Realizamos um levantamento geral das marcas escritas (metatextos como hashtags, símbolos e emojis ou textos simples) registradas pelos 
usuários no campo destinado à legenda em cada publicação. Tais marcas compõem a atual prática fotográfica e indicam uma das formas de entender a fotografia como uma prática de dados. Como é possível observar no gráfico da Figura 2, a utilização de metatextos é uma prática comum: 270 publicações (88,5\% da amostra) apresentam informação textual, hashtags ou emojis. Um número expressivo (58,6\% da amostra, 179 ocorrências) de publicações conta com hashtags ou emojis, sendo que sua presença simultânea se faz notar em apenas 57 publicações (18,6\%).

A pesquisa aponta que a prática fotográfica em rede social se configura como uma prática de escrita, descrição e interação através de símbolos, textos e narrativas construídas conjuntamente com a imagem em uma ampla rede com agências humanas (inserção voluntária de texto, escolha do objeto e local fotografado etc.) e algorítmicas específicas. A produção de metatextos é uma forma característica das novas conformações sociotécnicas em redes sociais digitais, alterando, inclusive, aspectos de relação com o espaço, as interações sociais e o desenvolvimento de narrativas de si. Apresentamos, a seguir, uma análise das publicações no Instagram através de três aspectos: 1. processo de espacialização; 2. processo de sociabilidade; 3. processo de produção de si (retratos e selfies).

\section{Processo de espacialização: relações com o local}

Processos de espacialização são relações sociotécnicas na constituição de territórios, lugares e espaços. A ação humana, através de símbolos e artefatos, cria formas de controle (território) que, em dinâmica extensiva e temporal, constituem os lugares. Estes, por associações, produzem o espaço. A ação humana é intrinsecamente espacializante. As mídias, como artefatos de ação da presença humana no espaço e no tempo, permitem formas de leitura e escrita do espaço, inscrevendo as relações sociais. Assim como Michel de Certeau (1990) tratou do andar como uma língua, podemos pensar nas mídias desenvolvendo gramáticas próprias na produção do espaço. No caso da fotografia em redes 
sociais, as componentes de geolocalização e os metatextos são elementos fundamentais para a criação de ações e discursos que constroem um imaginário do lugar.

A captura das imagens para análise se deu dentro de um universo restrito às publicações de caráter público e associadas à geolocalização. Como vimos, essa não é a única forma de identificação. Na amostra, há 402 referências ao espaço urbano (seja da imagem, seja em termos textuais). Há uma média de 1,3 indicação ao local em cada publicação para além da geotag, comum a todas. Percebem-se ainda 14 publicações que apresentam, ao mesmo tempo, três ou mais formas de referência ao espaço. A indicação da relação com o local é feita por meio de diferentes estratégias, às vezes com redundância. É o caso da publicação feita no perfil de uma criança, cuja legenda diz "Vamos lá”, apontando hashtags indexando \#patins e \#parquedacidade. Ou, em outro caso, utilizando a geotag da Praça Ana Lúcia Magalhães, no qual vemos um adulto segurando um bebê no colo com a legenda "Curtindo a pracinha com Zezo”. Ou então uma publicação na qual uma jovem aparece em pé em um gramado no Dique do Tororó, indicando as hashtags \#corridinha \#lifestyle (atividade física) e \#diquedotororo \#corridanodique (lugar). De forma semelhante, em outra publicação, identificam-se duas fotos mostrando o lago, os orixás e o estádio de futebol no Dique do Tororó e uma selfie com o rosto da pessoa ocupando parte do enquadramento, com as esculturas e o lago em segundo plano. Além das indicações na imagem, há ainda a legenda: "Conhecendo o \#dique e os orixás hoje e a \#arenafontenova de longe rs rs. \#salvador \#bahia".

É possível perceber comportamento semelhante em outras publicações, como essa realizada no Parque de Pituaçu (Figura 3). Vemos, no canto inferior esquerdo, parte de uma mão segurando um pedaço de melancia cortado em forma de coração; em segundo plano, uma visão ampla da lagoa e um entorno dominado por vegetações. Na legenda, há referência tanto ao tipo de local específico (um parque) quanto à cidade, e mesmo alguma demonstração de alegria em relação à estação do ano: "Calor de verão + melancia gelada + domingo no parque $=$ 
Salvamor", seguido de um emoji representando um coração. Não bastando as referências imagéticas e textuais - envolvendo verão, cidade e sentimentos relacionados a um domingo no parque -, há ainda um reforço em forma de hashtags, como "\#salvamor \#sunday \#beleza \#cidadelinda \#amor \#ssalovers".

Figura 3 - Diferentes referências ao local em uma mesma publicação.
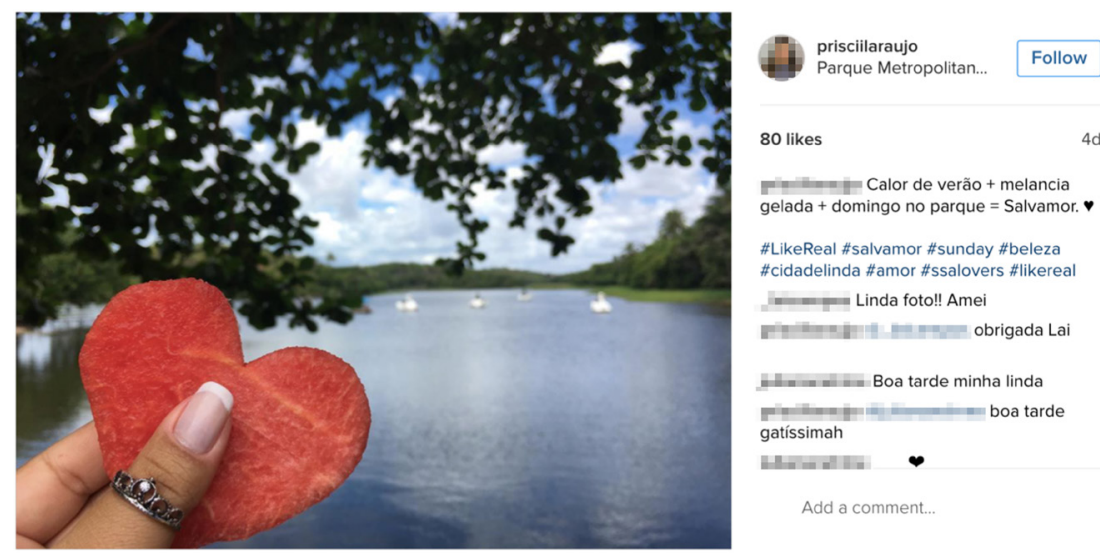
gelada + domingo no parque $=$ Salvamor $\vee$

\#LikeReal \#salvamor \#sunday \#beleza \#cidadelinda \#amor \#ssalovers \#likereal Fin Linda foto!! Amei

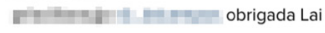

HII $=$ Bar $=$ Boa tarde minha linda

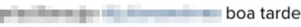
gatíssimah

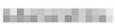

Add a comment.

$\mathrm{Na}$ amostra, percebemos que, além da geotag, as representações do local a partir da referência na paisagem, na hashtag, na legenda ou em segundo plano na imagem são práticas comuns. Podemos constatar que o processo de espacialização (SHIELDS, 1991) não se dá apenas pela circulação da imagem ou no momento de sua produção, mas através da inserção de metatextos que funcionam como referência ao local e à própria publicação, em uma prática narrativa sobre o espaço que se materializa em uma rede híbrida. Assim, o compartilhamento de fotos em rede social constitui hoje uma prática fotográfica que é intrínseca a uma prática de dados. Trata-se de uma modificação dos processos espacializantes da fotografia tradicional. É interessante perceber, nessa análise, como a materialidade do processo de espacialização se constitui por uma ampla rede que passa pelo local escolhido, pelo artefato utilizado, pelas formas de edição e manipulação da imagem, pelos metatextos (hashtags, legendas e símbolos), pelas geotags, pelo procedimento algorítmico da rede social, pelas formas de compartilhamento... 
A prática fotográfica opera, consequentemente, como um ator-rede performativo, algorítmico, muito diferente da prática de produção do espaço das fotos analógicas ou mesmo da fotografia digital antes do surgimento das redes sociais. Esse novo ambiente fotográfico possibilita aos usuários a criação de um discurso/narrativa e de uma prática sobre o espaço através de uma ampla rede de agências humanas e não humanas (LATOUR, 2005). Em níveis diferentes, a espacialização fotográfica está presente, seja de forma imagética, seja de forma textual, como uma prática aliada à lógica da produção de dados e da performatividade dos algoritmos. Como observamos, a prática fotográfica não se encerra no momento de produção da imagem, na praça ou no parque, e não se caracteriza apenas pelo compartilhamento, mas se constrói através da lógica de produção de dados e performances algorítmicas realizadas a partir das interações e inserções de metatextos. Os processos de espacialização, portanto, que também caracterizam essa prática fotográfica realizada em espaços urbanos, se desenvolve através de uma rede de processos que necessariamente inclui a produção de dados digitais - geolocalização, legendas, comentários, emojis, hashtags - e procedimentos algorítmicos próprios das redes sociais. A prática fotográfica, portanto, faz parte de uma rede de prática de dados.

\section{Processo de sociabilidade}

Com as redes sociais de fotografia, o que temos hoje são espaços ampliados de socialização através da produção, estocagem e circulação de imagens. Diferente da foto analógica - que tinha outra temporalidade de produção e formas específicas de circulação, mais lentas e centralizadas - ou da foto digital - feita com mais rapidez e efemeridade, mas, mesmo assim, com compartilhamento limitado -, as redes sociais de fotografia criam condições até então inexistentes de sociabilidade. As formas de sociabilidade pela prática da fotografia se ampliaram muito com as redes sociais dedicadas a essa área e contribuíram para a desconstrução da centralidade da imagem. No Instagram, o reforço da sociabilidade vem das legendas (textos simples, hashtags e emojis), ampliando o caráter não 
imagético e comunicacional das práticas fotográficas contemporâneas em rede social.

Nas publicações aqui analisadas, as formas de sociabilidade no espaço público se desenvolvem de maneiras diversas. ${ }^{8}$ Encontramos casais abraçados, pais passeando com seus filhos, grupos fazendo piquenique, ciclistas após uma pedalada, famílias praticando esportes, amigos passeando com seus cachorros etc. Há vários exemplos, como a selfie publicada por duas amigas comemorando o aniversário de uma delas (Figura 4a) em uma publicação com a geotag do Parque da Cidade e a legenda "Birthday Clara - Breve vídeos com fotos desse niver mais que legal! Bjss instafriends”. Misturando-se a diferentes emojis de coração, a legenda reafirma e produz uma continuidade narrativa com a representação imagética de proximidade. Em uma fotografia de duas amigas após atividade física realizada na Praça Ana Lúcia Magalhães (Figura 4b), as interações em formato textual completam a socialização. Há uma montagem com uma nova camada informacional textual acrescentada à própria foto, com a hashtag \#AmigasDaCorreria escrita em rosa, além de outras incluídas também na legenda.

Figura 4a - Selfie no Parque da Cidade.

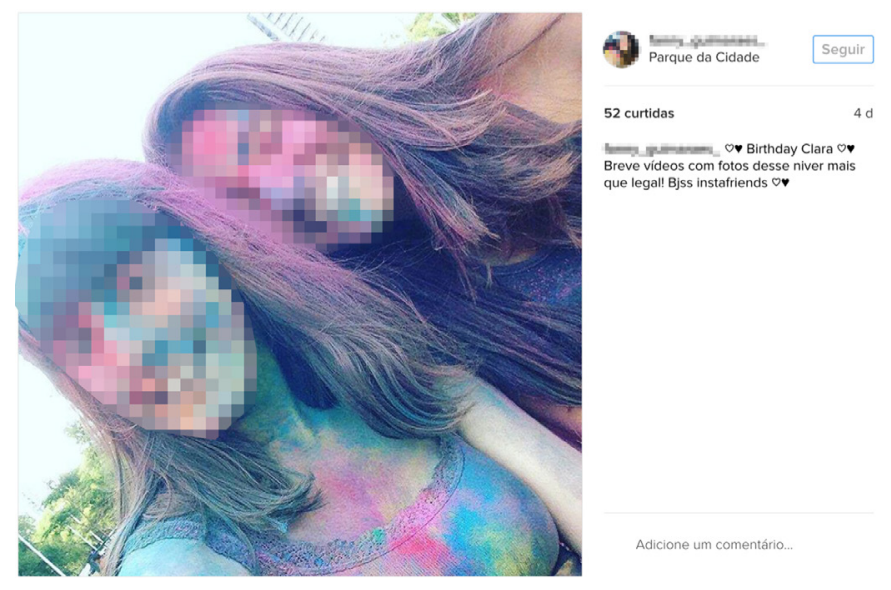

8 Há mais retratos nos quais aparecem duas ou mais pessoas (138) do que aqueles em que há apenas uma pessoa em primeiro plano (107). Percebe-se que, já no momento de tirar uma foto, há uma sociabilidade que aponta, muitas vezes, para uma atividade realizada em conjunto. 
Figura 4b - Retrato na Praça Ana Lúcia Magalhães.
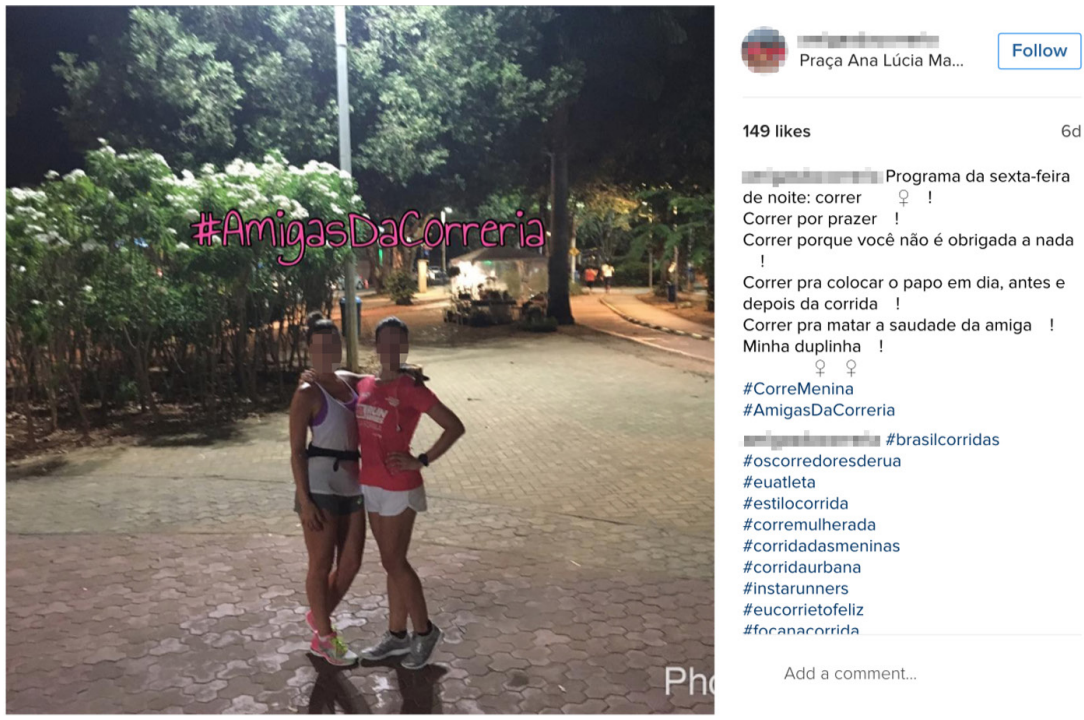

O mesmo acontece com grupos de pessoas. Há exemplos de encontros para comemorações de aniversários, chás de bebê, realização de atividades físicas, confraternizações com colegas de trabalho, familiares ou grupos religiosos. Neste último caso, observamos uma publicação (Figura 5a) na qual um grupo de 12 pessoas está sentado na grama em uma cena de piquenique. Nas hashtags, há referência ao local (\#parquedacidade) e ao caráter da atividade (\#ldschurch \#mormonchurch). Outro exemplo (Figura 5b), no Parque da Cidade, é uma montagem com cinco fotografias diferentes: uma selfie sozinho, outra selfie com três crianças ao fundo, um retrato dos oito membros da família, um adulto brincando com uma criança e, por fim, duas senhoras mais idosas interagindo entre si. A legenda completa mais uma vez a imagem: "Porque a vida é pra se viver", acompanhada das hashtags "\#viveremfamilia \#muitobom \#familiabasedetudo".

Há também perfis criados para cachorros, simulando uma possível autonomia de fala. Aqui, mais uma vez, o texto é fundamental e o uso de hashtags e legendas para compor os processos de espacialização e sociabilidade é evidente. Por exemplo, na publicação apresentada na Figura 
6 a, vemos a foto de um casal sentado com Mike, o dono do perfil. Na legenda, ele fala: "Porque eu amo os passeios ao lado dos meus pais, é muita brincadeira, muitos petiscos, correria e no fim fico cansadão", misturando diversos emojis e hashtags. Já na publicação seguinte (Figura 6b), vemos Theo e seus amigos, sem humanos. Na legenda, lê-se: "Quando você junta com sua trupe do coração...!!!". Nos comentários, a interação é realizada com outros perfis de cachorros - talvez aqueles que aparecem na foto -, demonstrando uma sociabilidade, implícita nos textos, dos donos através de seus cachorros. A prática conversacional de dados, nesses dois exemplos, mostra-se essencial para conduzir narrativamente, na interação entre imagem e metatextos, a presença e a relação ficcional dos animais na rede social.

Figuras 5a e 5b - Exemplos de fotos com grupos de pessoas.
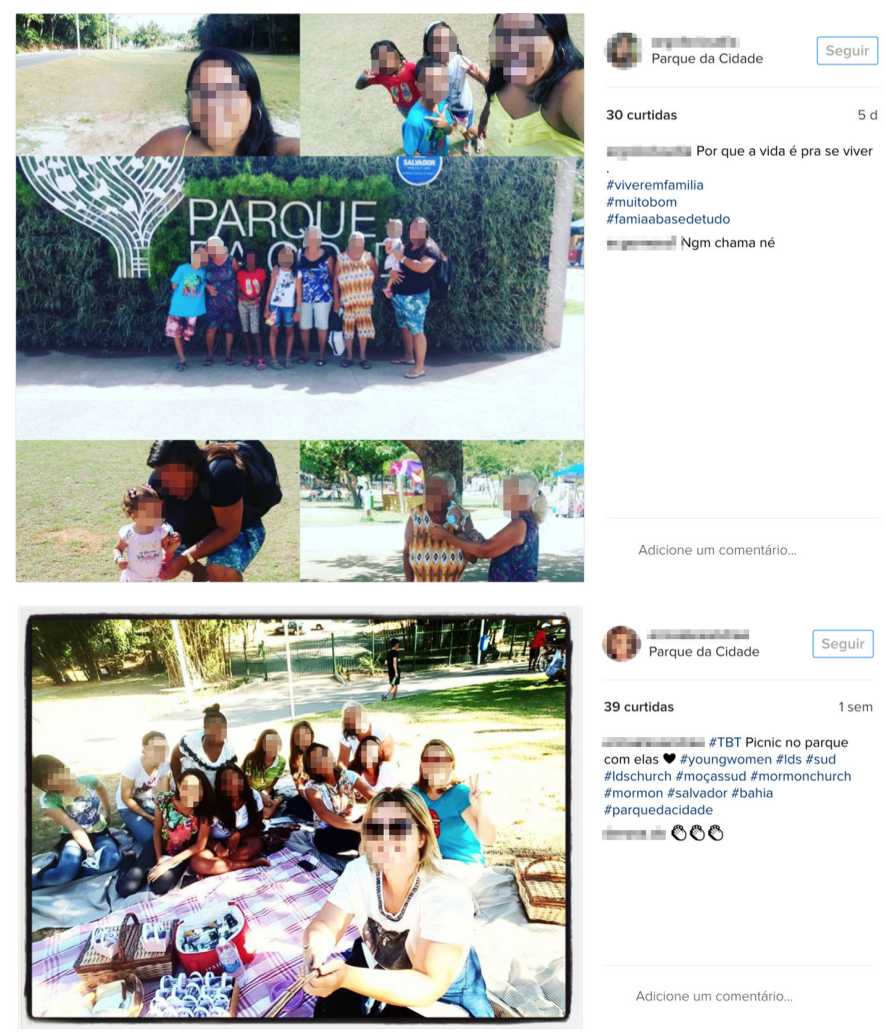

39 curtidas

com elas \#youngwomen \#Ids \#sud \#Idschurch \#moçassud \#mormonchurch \#mormon \#salvador \#bahia

\#parquedacidade

$+1+000$ 
Figuras 6a e 6b - Perfis no Instagram criados para cachorros.
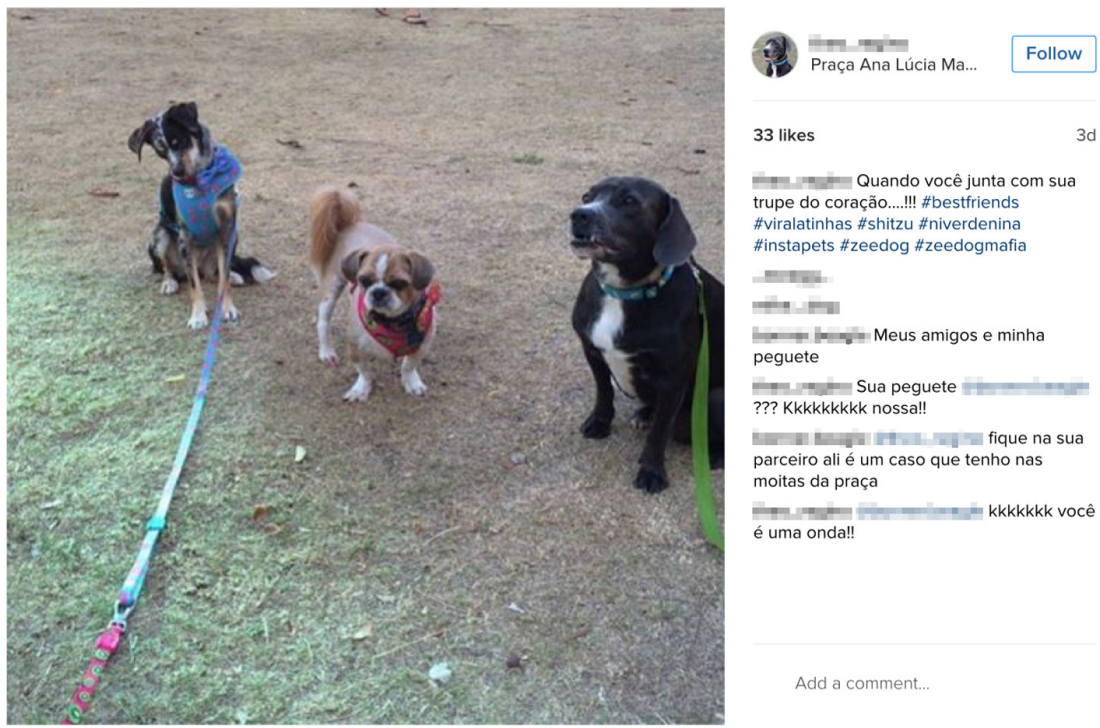

33 likes

Hin-1.1- Quando você junta com sua

trupe do coração...!!! \#bestfriends

\#viralatinhas \#shitzu \#niverdenina

\#instapets \#zeedog \#zeedogmafia

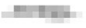

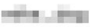

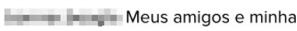

peguete

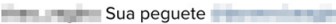

??? Kkkkkkkkk nossa!!

trat fique na sua parceiro ali é um caso que tenho nas moitas da praça

kㅐ = = kkkkkk você

é uma onda!!

Add a comment.

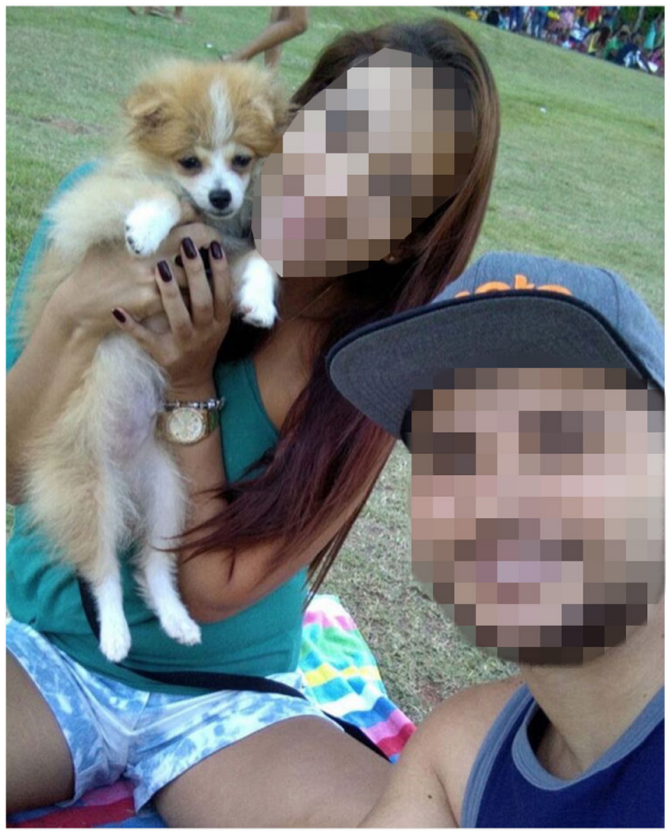

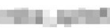

Parque da Cidade

12.1. Porque eu amo os passeios ao lado dos meus pais, é muita brincadeira, muitos petiscos, correria e no fim fico cansadão 1 :

\#doglovers \#luludapomerania \#spitzalemao \#mike \#spitzbahia \#pomeranian \#spitzpomerania in $=\theta \theta$

Assim, em vez de incorporar um caráter de atestação, valor estético ou de memória, as fotografias da nossa amostra se traduzem em 
termos comunicacionais, de relação com o outro, de compartilhamento e interação em uma ampla rede de agências. Essa prática fotográfica se caracteriza não apenas pela produção de uma imagem, mas pela disseminação de um conjunto de dados - marcações, comentários, metatextos, símbolos e geotags - criados para impulsionar as experiências de sociabilidade. Ou seja, a sociabilidade, nesse caso, é pautada pelas produções metatextuais, pelos procedimentos algorítmicos da plataforma e pela interação entre diferentes dados digitais. Argumentamos, portanto, que a prática fotográfica se coloca como uma prática conversacional de dados. Ela se insere em uma ampla rede de sociabilidade voltada para uma comunicação desenvolvida como produção de diversos metatextos que passam a compor a própria fotografia. Dessa forma, o uso das hashtags e legendas, por exemplo, indica um direcionamento expressivo, a confirmação do caráter comunicativo da prática fotográfica contemporânea, apontando para uma maior atenção à explicitação dos sentimentos de forma direta e inequívoca. Aqui, uma imagem não vale mil palavras. O local importa, a foto importa, mas tudo deve ser alinhavado pelo texto e pela prática de produção de dados - em legendas, hashtags, comentários, geotags e emojis.

\section{Processo de produção de sí: retratos e selfies}

Em 252 fotos, as pessoas são o objeto central (82\% do total). O lugar e as formas de sociabilidade aparecem tanto na foto quanto nos textos, ainda que estejam associados, por exemplo, a um tipo de retrato voltado imageticamente para si, como na selfie. Mesmo se tratando de um autorretrato, a selfie se desenvolve como uma prática de relação com o outro, de partilha de uma intimidade relacional (PASTOR, 2017). Escapando à imagem, essa relação com o outro se faz através dessa prática conversacional de dados, na produção constante de metatextos. Nos diferentes tipos de retrato (individual, grupal ou selfie), é possível observar a predominância da inserção textual (Figura 7). 
Figura 7 - Relação entre tipos de retrato e metatextos.

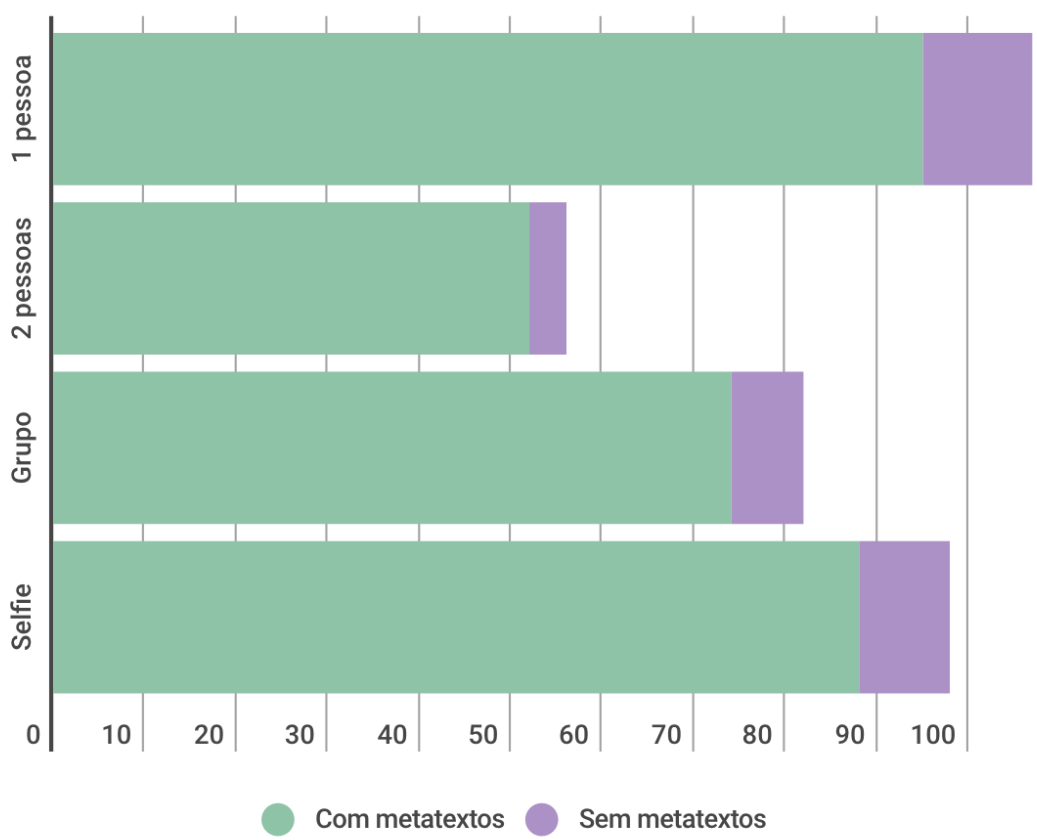

Tomemos como exemplo uma selfie tirada por um jovem no Dique do Tororó (Figura 8a). Realizado antes ou após uma corrida - como indica a hashtag \#running -, o autorretrato é complementado por três tipos de metatexto (hashtags, texto em legenda e emojis), todos fazendo referência à prática de exercício físico. Em outra, marcada com a geotag do Parque da Cidade, vemos um homem de meia-idade com boné, camisa regata e fones de ouvido, também correndo. Ele acrescenta à imagem uma informação da quilometragem e um desenho. Vemos mais uma vez metatextos em sobreposição à própria foto, processados através da performatividade algorítmica de outro aplicativo ${ }^{9}$

9 Trata-se provavelmente do aplicativo Nike+ Run Club. Ver http://www.nike.com.br/corrida/ app-nike-plus. 
Figuras 8a e 8b - Duas selfies tiradas, respectivamente, no Dique do Tororó e no Parque da Cidade.
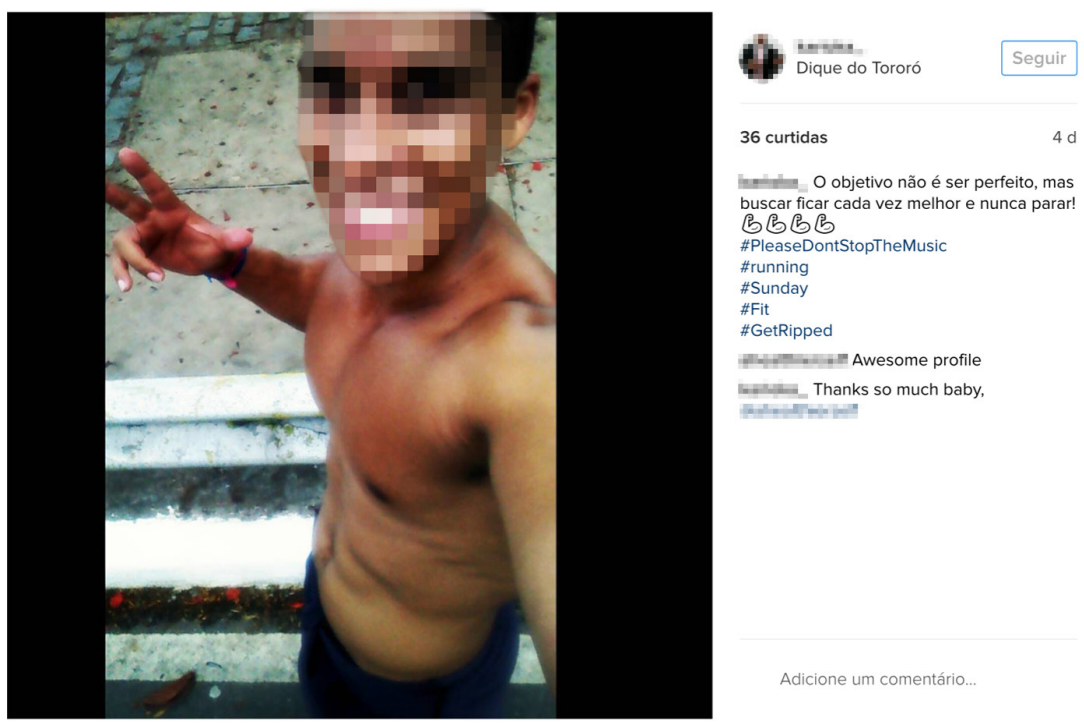

36 curtidas

$4 d$

linnin O objetivo não é ser perfeito, mas buscar ficar cada vez melhor e nunca parar! b占占

\#PleaseDontStopTheMusic

\#running

\#Sunday

\#Fit

\#GetRipped

Hillywim Awesome profile

nunile- Thanks so much baby,

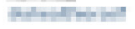

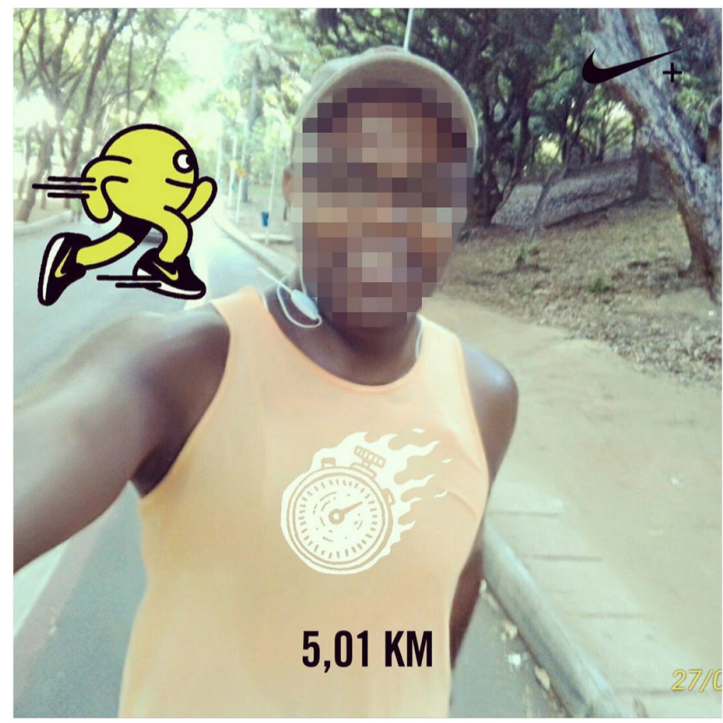

Parque da Cidade

Seguir

29 curtidas

는 Bom dia!

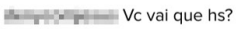

inmint=Bom dia amigo

I

Há também retratos coletivos. Encontramos 138 com duas ou mais pessoas ( $54 \%$ do total de retratos). Em uma dessas publicações (Figura 9a), vemos um tio com sua sobrinha - \#amordetio e \#tardeemfamilia 
Figuras 9a e 9b - Retratos com duas ou mais pessoas
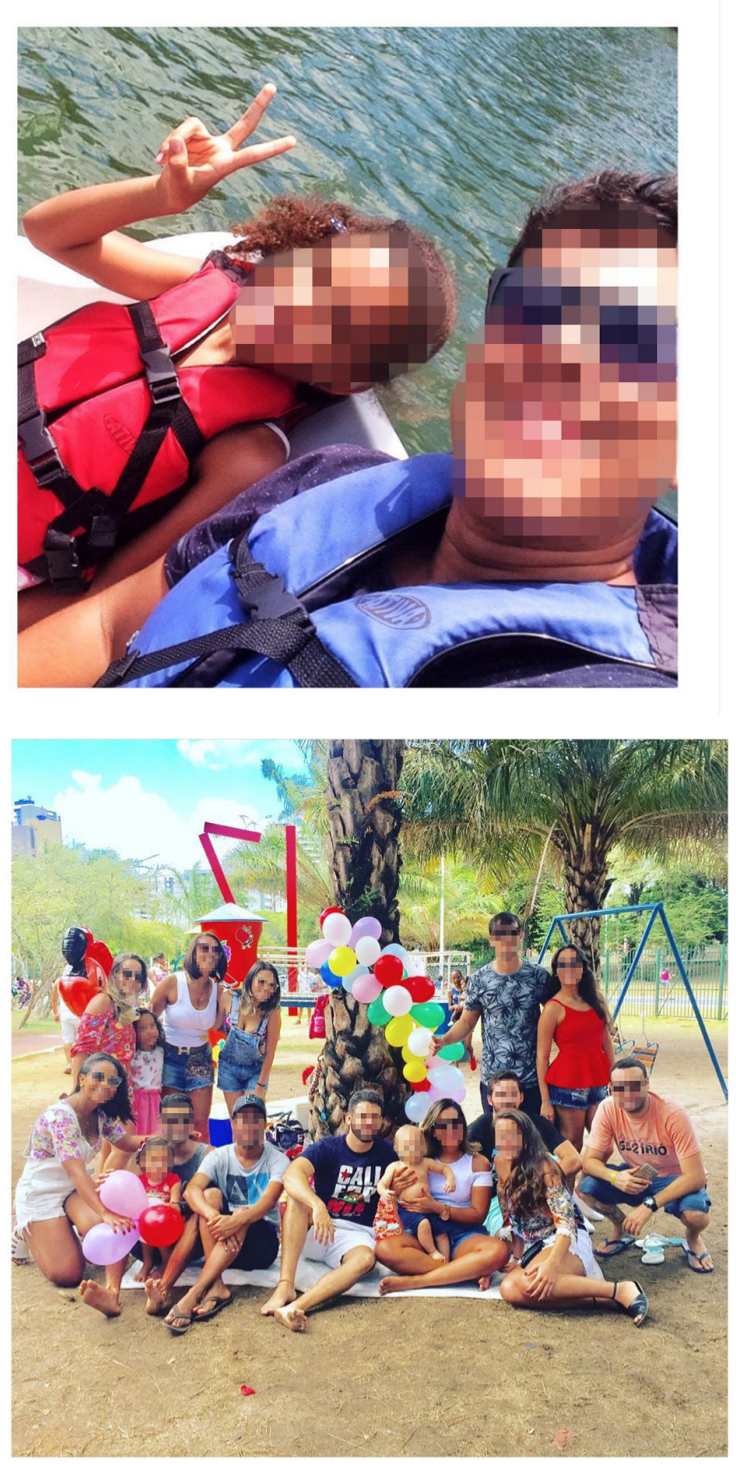

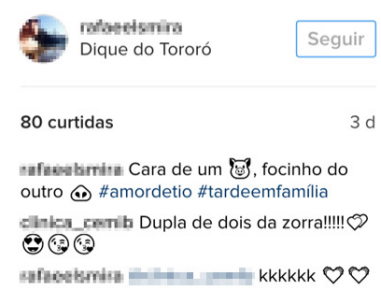

Adicione um comentário.

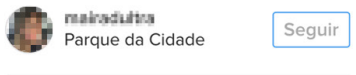

68 curtidas

$3 d$

Inningur int E ontem foi o aniversário do nosso LUCCA $\odot \odot$ \#tiaMaiama \#amizadeétudo \#meusmelhores \#obrigadatodos \#amodemais thatisy Foi maravilhoso $\infty$ lumandrastei \#amizadeétudo obrigado mai 9

milumagihanat Foi lindoo

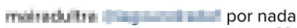
amigo! Lucca merece muito maiis $\varnothing$

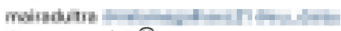
Graças a vocês!

mmariunarmasin Amei a iniciativa in-mill the Vocé é show!!!!

Adicione um comentário..

são as hashtags utilizadas. A selfie foi tirada no Dique do Tororó. Mesmo que os rostos ocupem o enquadramento quase por completo, é possível perceber, através da imagem e dos metatextos associados, que se trata de uma atividade ao ar livre em família. A legenda, misturando emojis e 
hashtags, descreve e compartilha o momento de interação. Ao mesmo tempo, a geotag indica o lugar (difícil de ser identificado apenas pela imagem). Em outra publicação, vemos um retrato com 16 pessoas no Parque da Cidade em uma comemoração de aniversário, como revelam a legenda e os balões. Misturando texto, hashtags e emojis, a autora da postagem desenvolve uma narrativa capaz de envolver, de maneira associativa, o dispositivo, a imagem - materializada em combinações numéricas -, as formas de compartilhamento, as interações em redes sociais, suas performances algorítmicas, as pessoas ali envolvidas, os metatextos registrados, os comentários etc.

A grande quantidade de retratos - incluindo selfies - disseminados em redes sociais, como esses aqui analisados, demonstram não um enfraquecimento dos processos de espacialização ou de sociabilidade, mas, ao contrário, um processo de produção de imagens de si que aponta para um caráter relacional.

\section{Conclusão}

As conclusões deste artigo encontram ecos parciais em diversos trabalhos de autores que discutem a relação entre fotografia, smartphones e redes sociais. Podemos citar a emergência de novos formatos de relações interpessoais através da imagem (RIVIÈRE, 2006); o caráter híbrido, de conexão e produção de imagem atrelado aos telefones celulares (LEMOS, 2007); as formas de intimidade e relações entre público e privado (LASÉN, 2013; LASÉN; GÓMEZ CRUZ, 2009); a rede sociotécnica pautada pela conectividade (GÓMEZ CRUZ e MEYER, 2012); a “imagem conversacional” (GUNTHERT, 2014); a relação da fotografia com softwares, algoritmos, metadados e o espaço urbano (HOCHMAN, 2014; HOELZL; MARIE, 2016; MANOVICH, 2016), entre outros. Há mudanças nas relações com os lugares e com a prática fotográfica mediada por aplicativos (BOULLIER, 2014) e nas interações que se configuram não apenas no momento da própria ação de fotografar, mas também nos rastros de sociabilidade e dados gerados e propagados em 
uma continuidade da experiência. Borram-se as fronteiras entre imagem e dado, transformando a vivência urbana e a própria cidade (HOELZL; MARIE, 2016; SCHWARTZ; HOCHMAN, 2014).

No entanto, o que parece ainda não estar sendo dito é como a nova prática fotográfica se institui como um ator-rede que tem na prática de dados, na performatividade algorítmica do sistema e nas formas de compartilhamento em rede social um dos seus elementos centrais. Nenhum deles atesta, como apontamos nesta pesquisa, o caráter da fotografia em rede social como uma prática de dados e de performatividade algorítmica através de metatextos, de uma narrativa complementar à imagem. A imagem é importante, certamente, mas o processo de mediação se dá, de agora em diante, a partir de um amplo movimento de produção de performances maquínicas e de dados. Portanto, chamamos de "prática fotográfica" esse ator-rede, essa sensibilidade performativa (LEMOS; BITENCOURT, 2017), essa comunicação das coisas (LEMOS, 2013), e não apenas o momento no qual se produz uma imagem a partir de um clique na tela de um smartphone ou mesmo o seu simples compartilhamento.

Toda ação fotográfica dispara agências em uma ampla rede de atores, isso desde os primeiros artefatos analógicos até as câmeras digitais. $\mathrm{O}$ que apontamos aqui não é a novidade dessa ação fotográfica como ator-rede, mas a emergência de um novo processo fotográfico que se faz em uma rede de performances algorítmicas associadas a metatextos, pautada por uma prática de produção de dados que funciona como um dos elementos principais nas trocas comunicacionais. Ou seja, uma ampla rede performática que passa pela foto, pela experiência de relação com o outro, pelo espaço, os algoritmos que a interpretam, os comentários e interações em redes sociais, além das diferentes materialidades que a compõem - metadados, legendas, hashtags, geotags, emojis etc. Nesse entrelaçamento de dados, desenvolve-se uma nova prática fotográfica que não se resume à imagem e que tem no compartilhamento e na produção de metatextos seu momento central. 
A prática fotográfica com o Instagram, portanto, constitui um importante mediador nos processos de espacialização e sociabilização (em grupo, individual ou selfies), como um tradutor de formas comunicacionais da fotografia hoje. A prática fotográfica se transforma de uma captura de imagens tecnicamente cuidadas, funcionando como uma memória social, para um processo comunicacional mais amplo, envolvendo o local, a preparação - com a escolha de poses e imagens -, o momento lúdico, o compartilhamento e o reforço informacional de legendas, comentários e hashtags. Para utilizar o termo de André Gunthert (2014), temos uma imagem conversacional, mas na lógica dos dados e dos algoritmos do sistema em questão. Essa propriedade conversacional ultrapassa a própria imagem, nos permitindo pensar na prática fotográfica como um conjunto de produções de dados digitais.

\section{Referências}

700 MILLION. Instagram, 26 abr. 2017. Disponível em: <http://blog.instagram.com/ post/160011713372/170426-700million>. Acesso em: 31 ago. 2017.

BOULLIER, D. Habitele: mobile technologies reshaping urban life. URBE, v. 6, n. 1, 2014.

BOURDIEU, P. Un art moyen: essai sur les usages sociaux de la photographie. Paris: Les Éditions de Minuit, 1965.

CERTEAU, M. de. L'invention du quotidien: arts de faire. Paris: Gallimard, 1990.

GÓMEZ CRUZ, E.; MEYER, E. T. Creation and control in the photographic process: iPhones and the emerging fifth moment of photography. Photographies, v. 5, n. 2, p. 203-221, 2012.

GUNTHERT, A. L'image conversationnelle: les nouveaux usages de la photographie numérique. Études photographiques, v. 31, p. 55-71, 2014.

HJORTH, L.; HENDRY, N. A snapshot of social media : camera phone practices. Social Media + Society, v. 1, n. 3, p. 1-3, 2015.

HJORTH, L.; PINK, S. New visualities and the digital wayfarer: Reconceptualizing camera phone photography and locative media. Mobile Media \& Communication, v. 2, n. 1, p. 40-57, 2014.

HOCHMAN, N. The social media image. Big Data ש Society, v. 1, n. 2, p. 1-15, 2014. 
HOELZL, I.; MARIE, R. Brave new city : the image in the urban data-space. Visual Communication, v. 15, n. 3, p. 371-391, 2016.

LASÉN, A. Autoportraits numériques: un exemple de la médiation technologique du devenir des corps. In: GRANDJEAN, N.; LOBET-MARIS, C. (Orgs.). Corps et Technologies: penser l'hybridité. Bruxelas: P.I.E. Peter Lang, 2013. p. 83-110.

LASÉN, A.; GÓMEZ CRUZ, E. Digital photography and picture sharing: redefining the public/private divide. Knowledge, Technology \& Policy, v. 22, p. 205-215, 2009.

LATOUR, B. Reassembling the Social. Nova York: Oxford University Press, 2005.

LEMOS, A. A comunicação das coisas: teoria ator-rede e cibercultura. São Paulo: Annablume, 2013.

Comunicação e práticas sociais no espaço urbano: as características dos Dispositivos Híbridos Móveis de Conexão Multirredes (DHMCM). Comunicação, Mídia e Consumo, v. 4, n. 10, p. 23-40, 2007.

.; BITENCOURT, E. Sensibilidade performativa e comunicação das coisas: explorando as narrativas algorítmicas na Fitbit. In: ENCONTRO ANUAL DA COMPÓS, XXVI, 2017, São Paulo. Anais... São Paulo: Faculdade Cásper Libero, 6-9 jun. 2017. Disponível em: <http://www.compos.org.br/data/arquivos_2017/trabalhos_arquivo_5Q Y2MEG65VUCUM0GJGQU_26_5576_16_02_2017_08_40_02.pdf >. Acesso em: 31 ago. 2017.

LENSVID EXCLUSIVE: what happened to the photography industry in 2016? LensVid, [2017?]. Disponível em: <https://ensvid.com/gear/lensvid-exclusive-happened-photography-industry-2016/>. Acesso em: 31 ago. 2017.

LUPTON, D. Personal data practices in the age of lively data. In: DANIELS, J.; GREGORY, K.; MCMILlAN COTTOM, T. (Orgs.). Digital Sociologies. Bristol: Policy Press, 2016. p. 339-354.

MANOVICH, L. Exploring urban social media: Selfiecity and on Broadway. Code and the City, 2016. Disponível em: <http://manovich.net/content/04-projects/083-urbansocialmedia/manovich_exploring_urban_social_media_edit.pdf $>$. Acesso em: 31 ago. 2017.

PASTOR, L. Prática do selfie: experiência e intimidade no cotidiano fotográfico. Contracampo, v. 36, n. 2, p. 157-173, 2017.

RIVIÈRE, C. A. Téléphone mobile et photographie: les nouvelles formes de sociabilités visuelles au quotidien. Societes, v. 91, n. 1, p. 119-134, 2006.

SCHWARTZ, R.; HOCHMAN, N. The social media life of public spaces: reading places through the lens of geo-tagged data. In: WILKEN, R.; GOGGIN, G. (Eds.). Locative media. Nova York: Routledge, 2014.

SHIELDS, R. Places on the margin: alternative geographies of modernity. Londres: Routledge, 1991.

SMARTPHONES dominate Flickr uploads in 2016. Flickr Blog, 6 dez. 2016. Disponível em: <http://blog.flickr.net/2016/12/06/smartphones-dominate-flickr-in-2016-apple-leads/>. Acesso em: 31 ago. 2017. 


\section{Sobre os autores}

Leonardo Pastor - Doutorando do Programa de Pós-graduação em Comunicação e Cultura Contemporâneas da Facom/UFBA e pesquisador do Lab404 (Póscom/UFBA).

André Lemos - Professor titular da Facom/UFBA. Pesquisador 1A do CNPq e diretor do Laboratório de Pesquisa em Mídia Digital, Redes e Espaço (Lab404) do Programa de Pós-graduação em Comunicação e Cultura Contemporâneas (Póscom/UFBA).

Data de submissão: 31/12/2017

Data de aceite: 20/03/2018 